\title{
Organ of Special Sense
}

National Cancer Institute

\section{Source}

National Cancer Institute. Organ of Special Sense. NCI Thesaurus. Code C33224.

Anatomic structures in the head responsible for special sensations rather than general sensations. This category includes the eyes, ears, nose, and tongue. 